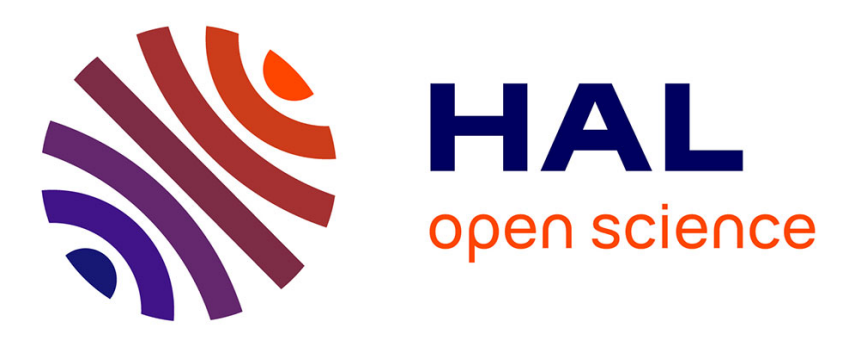

\title{
Towards Mid-IR Pulsed All-Fiber Lasers Based on Saturable Absorbers
}

Pascal Paradis, Vincent Fortin, Bernard Dussardier, Real Vallee, Martin

Bernier

\section{- To cite this version:}

Pascal Paradis, Vincent Fortin, Bernard Dussardier, Real Vallee, Martin Bernier. Towards Mid-IR Pulsed All-Fiber Lasers Based on Saturable Absorbers. 2020 IEEE Photonics Conference (IPC), Sep 2020, Vancouver, Canada. pp.1-2, 10.1109/IPC47351.2020.9252433 . hal-03058331

\section{HAL Id: hal-03058331 https://hal.science/hal-03058331}

Submitted on 11 Dec 2020

HAL is a multi-disciplinary open access archive for the deposit and dissemination of scientific research documents, whether they are published or not. The documents may come from teaching and research institutions in France or abroad, or from public or private research centers.
L'archive ouverte pluridisciplinaire HAL, est destinée au dépôt et à la diffusion de documents scientifiques de niveau recherche, publiés ou non, émanant des établissements d'enseignement et de recherche français ou étrangers, des laboratoires publics ou privés. 


\title{
Towards Mid-IR Pulsed All-Fiber Lasers Based on Saturable Absorbers
}

\author{
Pascal Paradis \\ Center for Optics, Photonics and Lasers \\ Université Laval \\ Québec, Canada \\ pascal.paradis.2@ulaval.ca \\ Bernard Dussardier \\ Institut de Physique de Nice \\ Université Côte d'Azur, CNRS \\ Nice, France \\ bernard.dussardier@unice.fr
}

\author{
Vincent Fortin \\ Center for Optics, Photonics and Lasers \\ Université Laval \\ Québec, Canada \\ vincent.fortin@copl.ulaval.ca \\ Réal Vallée \\ Center for Optics, Photonics and Lasers \\ Université Laval \\ Québec, Canada \\ rvallee@ copl.ulaval.ca
}

\author{
Martin Bernier \\ Center for Optics, Photonics and Lasers \\ Université Laval \\ Québec, Canada \\ martin.bernier@ulaval.ca
}

\begin{abstract}
We present our preliminary design and propositions towards an all-fiber mode-locked linear laser cavity operating at 2.8 microns based on a heavily erbium-doped fluoride fiber bounded by a semiconductor saturable absorber mirror and a fiber Bragg grating generates stable pulses as short as 15 ps.
\end{abstract}

Keywords—fiber, laser, ultrafast, components, nonlinear

\section{INTRODUCTION}

Mid-infrared (mid-IR) pulsed fiber lasers are promising for biomedical applications such as dental tissue ablation, cardiovascular surgery and vitreoretinal surgery due to the strong water absorption peak at $2.94 \mu \mathrm{m}$ [1], [2]. The emission spectrum of these lasers can also reach the fundamental rotation-vibrational resonances of many atmospheric pollutants such as methane [3]. Thus, they would enable advantageous field applications such as remote sensing with mid-IR spectroscopy.

In recent years, a multitude of ultrafast fiber lasers operating near $3 \mu \mathrm{m}$ have been reported. Ring lasers using nonlinear polarization evolution generated the shortest pulses while those using saturable absorber (SA) emitted pulses as short as 6 ps [4], [5]. A simpler linear mode-locked fiber laser based on a semiconductor saturable absorber mirror (SESAM) and a fiber Bragg grating (FBG) was also reported, producing 60 ps pulses limited by the narrow FBG bandwidth [6]. A more traditional mode-locked fiber based on a SESAM and a broadband output coupler generated 25 ps pulses [7]. However, the complexity, building cost and alignment requirements of these lasers restrict their field deployment and limit their usage to laser experts.

In this paper, we present a mode-locked erbium-doped fluoride fiber laser based on a fiber Bragg grating (FBG) and a SESAM, generating $15 \mathrm{ps}$ pulses at $2.825 \mu \mathrm{m}$ with $150 \mathrm{~mW}$ average output power at a repetition rate of $55 \mathrm{MHz}$ as a step towards ultrafast allfiber lasers emitting in the mid-IR.

\section{EXPERIMENTAL SETUP}

The laser setup, as illustrated in fig. 1a is made of a $2 \mathrm{~m}$-long $7 \% \mathrm{~mol} \mathrm{Er}^{3+}$-doped fluoride fiber (Le Verre Fluoré) as the gain medium for the laser cavity bounded by a SESAM (BATOP GmbH) and a fiber Bragg grating (FBG) written using femtosecond pulses through the fiber's protective coating to preserve its original robustness [8]. The gain fiber is backward pumped with a $976 \mathrm{~nm}$ pump diode from (Alfalight, B33125) to simplify the intracavity alignment and achieve higher output power than in a forwardpumping scheme. The FBG has a peak reflectivity of $65 \%$ at $2790.9 \mathrm{~nm}$ with a FWHM of $3.2 \mathrm{~nm}$. The aspherical ZnSe lenses have focal lengths of $25 \mathrm{~mm}$ at the output and $12.5 \mathrm{~mm}$ inside the cavity, and each of them transmits around $95 \%$ of the signal at $2.8 \mu \mathrm{m}$. The fiber tips are angle-cleaved at $8^{\circ}$ to eliminate parasitic reflections thus achieving stable mode-locking and the residual pump power is removed by the dichroic mirror (DM) to avoid damaging the SESAM.

Moreover, we propose the use of a fiber-based saturable absorber mirror (SAM) and a pump combiner, as shown in fig. 1b, to achieve a robust pulsed all-fiber linear laser emitting around $2.8 \mu \mathrm{m}$. 
a)

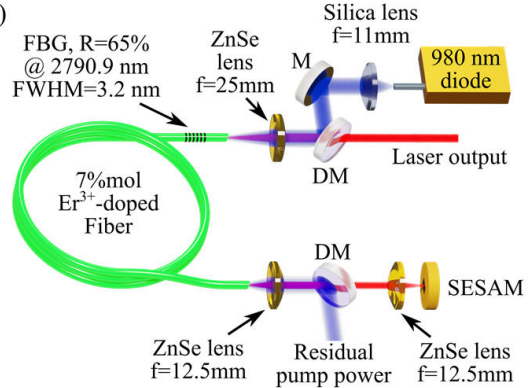

b)

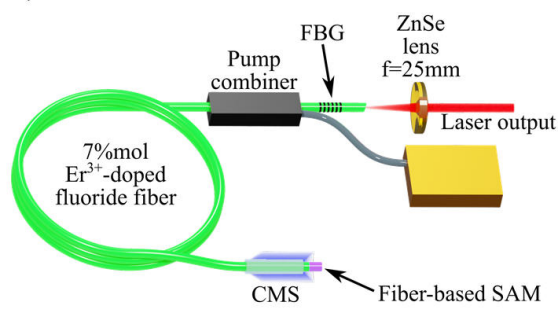

Fig. 1. a) Experimental setup of the mode-locked $\mathrm{Er}^{3+}$-doped fiber laser based on a SESAM and an FBG. b) Proposed experimental setup for the mode-locked $\mathrm{Er}^{3+}$-doped fiber laser based on a SA fiber and an FBG. (CMS: cladding mode stripper, DM: dichroic mirror, M: gold mirror)

\section{RESULTS}

This mode-locked laser cavity generates 15 ps pulses with a time-bandwidth product of 0.380 , i.e., close to the Fourier-Transform limit as shown in fig. 2. The mode-locked regime is self-starting without any Q-switched regime at lower pump power if the alignment of the intracavity components is optimal. The mode-locked regime is stable with one pulse per round trip between $87.5 \mathrm{~mW}$ and $157.5 \mathrm{~mW}$ of average output power. At higher power, the mode-locked regime became unstable with two pulses per round trip with longer pulse duration. Moreover, the emission spectrum is centered on the FBG's minimum transmission (i.e. on its maximum reflectivity) which indicates that the duration and the spectrum can be controlled by the FBG's properties in this design if the total cavity dispersion is low enough in the anomalous regime and the SA's recovery time is short enough, its modulation depth is not too shallow and the saturation fluence is high enough.
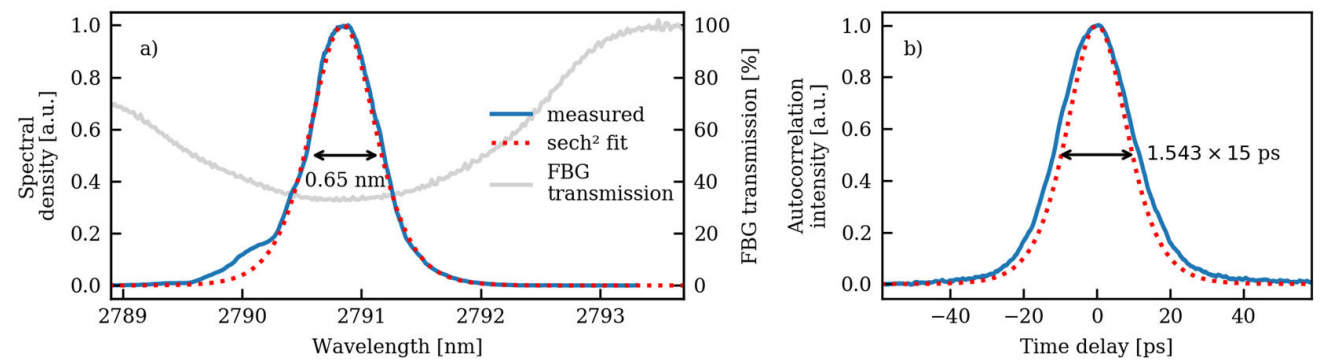

Fig. 2. a) Experimental spectral density and FBG transmission spectrum and b) duration of the pulse generated by the laser source

\section{CONCLUSION}

We present a simple mode-locked fiber laser design based on a SESAM and a FBG that allows control of the duration and the bandwidth of the pulses. While being much simpler than ultrafast ring lasers operating in Mid-IR with a saturable absorber, this laser design was able to generate $15 \mathrm{ps}$ pulses close to the Fourier-transform limit. During the presentation, different new configurations of fiber-based SA mirror will be discussed to greatly improve the robustness and reliability of ultrafast mid-IR lasers.

\section{REFERENCES}

[1] X. Zhu et al., "Pulsed fluoride fiber lasers at $3 \mu \mathrm{m}$ [Invited]," J. Opt. Soc. Am. B, vol. 34, no. 3, p. A15, Mar. 2017

[2] S. Amini-Nik et al., "Ultrafast Mid-IR Laser Scalpel: Protein Signals of the Fundamental Limits to Minimally Invasive Surgery," PLoS One, vol. 5, no. 9, p. e13053, Sep. 2010, doi: 10.1371/journal.pone.0013053.

[3] F. K. Tittel, D. Richter, and A. Fried, "Mid-Infrared Laser Applications in Spectroscopy," in Solid-State Mid-Infrared Laser Sources, Berlin, Heidelberg: Springer Berlin Heidelberg, 2003, pp. 458-529.

[4] S. Antipov, D. D. Hudson, A. Fuerbach, and S. D. Jackson, "High-power mid-infrared femtosecond fiber laser in the water vapor transmission window," Optica, vol. 3 , no. 12, p. 1373 , Dec. 2016

[5] T. Hu, D. D. Hudson, and S. D. Jackson, "Stable, self-starting, passively mode-locked fiber ring laser of the 3 um class," Opt. Lett., vol. 39, no. 7, p. 2133, Apr. 2014

[6] A. Haboucha, V. Fortin, M. Bernier, J. Genest, Y. Messaddeq, and R. Vallée, "Fiber Bragg grating stabilization of a passively mode-locked 28 um Er3+: fluoride glass fiber laser," Opt. Lett., vol. 39, no. 11, p. 3294, Jun. 2014

[7] P. Tang et al., "Watt-level passively mode-locked Er^3+-doped ZBLAN fiber laser at 28 m," Opt. Lett., vol. 40, no. 21, p. 4855, Nov. 2015

[8] J. Habel et al., "Femtosecond FBG Written through the Coating for Sensing Applications," Sensors (Basel) 17(11), 2519, 2017 